\title{
HYDRAULIC CHARACTERISTICS OF FLOW-THROUGH BRIDGE OPENINGS
}

\author{
UDC:532.5
}

Original scientific paper

https://doi.org/10.18485/aeletters.2021.6.1.3

\author{
Saad Mulahasan ${ }^{1}$, Ahmed Y. Mohammed ${ }^{2}$ \\ ${ }^{1}$ Al-Mustansiriyah University, Water Resources Engineering Department, Baghdad, Iraq \\ ${ }^{2}$ University of Mosul, College of Engineering, Dams and Water Resources Department, Mosul, Iraq
}

\begin{abstract}
:
Flow-through a bridge opening may run either partially or fully. In this research, backwater rise, hydraulic loss coefficient, and drag coefficient for two bridge models and three flow conditions are investigated. Based on the dimensional analysis theory, an equation was developed to calculate the water level difference $\Delta h$ between the upstream and the downstream for the bridge models. Results showed that the derived equation of the backwater rise is valuable to the experimental data which showed a percentage error not exceed $5 \%$. The hydraulic loss coefficient $C L$ and the drag coefficient $C_{D}$ were calculated. The drag coefficient values for the lateral constriction models are ranged from 0.5 to 2.0, and for the submerged bridge, the model was in the range of (0.5-3.5) with an average of 2.1. The impact of the blockage ratio on the hydraulic loss coefficient showed an increase of 1-2 times when the blockage was changed from 0.70 to 0.483 .
\end{abstract}

\section{ARTICLE HISTORY}

Received: 31.01.2021.

Accepted: 10.03.2021.

Available: 31.03.2021.

\section{KEYWORDS}

Loss coefficient; bridge opening; open channel flow, pier, drag coefficients

\section{INTRODUCTION}

The increasing population in the world leads to an increase in the number of bridges. The problem of the obstructed open channels by bridge piers and abutments with the flow of water is becoming more important at high flowrates especially at periods of flood events. The increase in the water level upstream the structure is a function of the contraction ratio $(B / W)$, where $B$ and $W$ are the free flow width and channel width respectively Fig.1a. When the flow runs below the upper edge of a lateral constriction (abutment), the flow condition is defined as free flow, while a submerged orifice flow occurs when the flow runs completely below the upper edge of the bridge deck. Otherwise, when the flow exceeds the upper edge of the deck slab the flow is then called overtopping or broad crested weir flow Fig.1b. Energy loss and vortices are usually associated with the water level rise due to the vicinity of the obstacle. The most common types of vortices were observed at many locations around the constriction [1-3], these vortices play a crucial reason for the development of the head loss between the upstream and downstream of the structure.

The hydraulic loss coefficients for the contraction and the expansion reaches were investigated by [4]. It was found four parameters, the length of expansion reach, the length of contraction reach, the expansion coefficient, and the contraction coefficient that are very important in hydraulic modeling. Prediction of the water surface profile in the vicinity of an obstacle under free and submerged flow conditions has been carried out by several researchers [5-7]. An empirical relationship based on 2,600 experiments to predict the deformed water surface profile at bridge piers and abutments was investigated [8]. The author focused on the effect of the magnitude of channel contraction upon the height of the backwater curve for different pier shapes and contraction ratios. The results showed that the loss coefficient varies considerably for different channel 
constrictions. Flow patterns and water surface profile were studied in an open channel with several constriction openings [9]. An expression of the head loss coefficient was then derived in terms of the obstructed bridge area. An experimental study was carried out to investigate an empirical equation of the backwater curve and specific discharge under free and submerged bridge deck conditions and then compared to the most applicable theoretical equations [10].

An experimental study of the three-dimensional flow field in a rectangular cross-section cylinder placed on the sidewall of a rectangular open channel was studied [11], the velocity and the bed shear stress were found to be 1.6 and 3.3 times their magnitudes in free flow. Flow measurements such as velocity and turbulence characteristics around bridge scoured piers were studied $[12,13]$. The three-dimensional flow field was measured and the distributions of time-averaged velocity components, turbulence intensity components and Reynolds shear stresses at different vertical sections are studied and estimation of scour depth at bridge abutments.

The large-eddy simulation was used to investigate the flow patterns through a bridge physical model [14]. A good estimation of the complex flow turbulence around the bridge model featuring various large-scale structures around the bridge was elucidated. The velocity profile behind an over-flooded obstacle was experimentally investigated in a rectangular laboratory flume using $A D V$ and numerically simulated using the CFD technique [15]. Submerged orifice flow and overtopping flow conditions in a movable bed were experimentally investigated in a bridge physical model [16]. The laboratory study showed that increasing the velocity gradients close to the bed results in a higher rate of bed sediment transport. The relationships between the velocity gradients measured close to the bed and the degree of flow contraction through the bridge was also investigated for scour measurements. Flow over submerged bridge deck models with various aspect ratios was numerically simulated using ANSYS FLUENT [17]. It showed that the investigated free surface profiles, drag coefficients, and vortices can be valuable predicting using such technique. As the aspect ratio increases, the distance where the shear layers from an upper and lower side of the deck meet also decreases. The largest values of the mean drag coefficient are found for aspect ratio $L / D=2$.
In the case of the aspect ratio $L / D>2$, as the aspect ratio increases, the drag coefficient decreases.

Many studies dealt with hydraulics characteristics around the pier and this part studied expansively, while hydraulic characteristics and hydraulic loss coefficient near bridge abutments are probably few and this part still need to expand to studded hydraulically and structurally, so this research focuses on the hydraulic characteristics of flow through bridge openings under subcritical flow state to predicting the backwater rise, hydraulic loss and drag coefficients at three different flow conditions. These are free flow (flow passage below a bridge with a lateral abutment), orifice flow, and weir flow (flow through a submerged bridge opening with overtopping).

\section{EXPERIMENTAL SET-UP}

Experiments were carried out in a glass-walled flume of $10 \mathrm{~m}$ long and $30 \mathrm{~cm}$ wide with a bed slope of $0.05 \%$. A sidewall abutment (lateral constriction) and submerged rectangular bridge models were used. Two sidewall abutment sizes were tested, Ls $=20 \mathrm{~cm}$ and $9 \mathrm{~cm}$ in the direction of the flow and of width perpendicular to the flow direction, $L C=15.5$ $\mathrm{cm}$ and $9 \mathrm{~cm}$ which results in an opening ratio (B/W) of 0.483 and 0.70 respectively Fig.1a. For the submerged bridge deck model, the bridge consists of an abutment, $L=10 \mathrm{~cm}$ in the direction of the flow and width $b=9 \mathrm{~cm}$, and height of $h_{0}=5.0 \mathrm{~cm}$. The other details of the bridge deck are the deck thickness, $h_{\mathrm{t}}=24 \mathrm{~mm}$, which extended across the channel length Fig.1b and c. The geometric contraction ratio of bridge opening width to channel width was 0.70 .

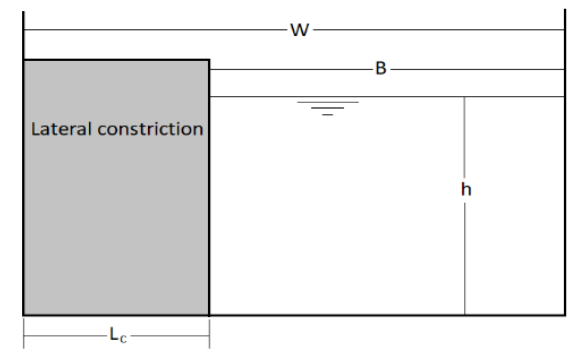

a)

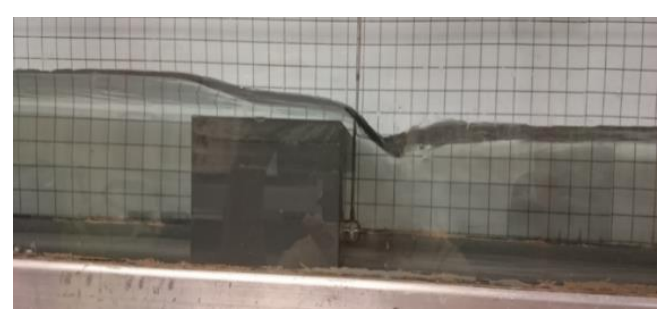

b) 


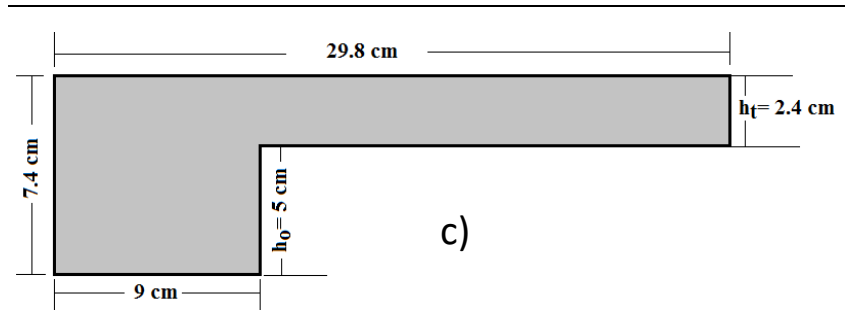

Fig. 1 a) Schematic diagram of the channel cross-section in the vicinity of a lateral constriction, (b) Photograph of the laboratory experiment with a submerged rectangular bridge model, (c) The physical bridge model

Water level measurements were carried out using a point gauge with an accuracy of $\pm 0.01 \mathrm{~mm}$. Point locations of water level measurements for the submerged rectangular bridge model were carried out along the mid-width of the flume. Point locations were carried out at each $1.0 \mathrm{~cm}$ along the length of the bridge structure in the flow direction. Upstream of the bridge, the first measurement locations were taken at each $1 \mathrm{~cm}$ from the bridge edge for $5 \mathrm{~cm}$, and further measurements were taken at each $10 \mathrm{~cm}$ for $1 \mathrm{~m}$. Measurements of the downstream position of the bridge were located at each $1 \mathrm{~cm}$ for the first $5 \mathrm{~cm}$ from the downstream bridge edge and at each $5 \mathrm{~cm}$ in the first $0.5 \mathrm{~m}$ and then at each $10 \mathrm{~cm}$ for a further $1 \mathrm{~m}$.

Uniform flow conditions were established before inserting the bridge models into the flume working section for some discharges ranged from 2 $\mathrm{l} / \mathrm{sec}$ to $15 \mathrm{l} / \mathrm{sec}$, Table 1 . Three flow conditions were established; free flow, orifice flow, and weir flow. For inundated bridge deck, four flowrates were used $7.0 \mathrm{l} / \mathrm{sec}, 8.5 \mathrm{l} / \mathrm{sec}, 12 \mathrm{l} / \mathrm{sec}$ and $15 \mathrm{l} / \mathrm{sec}$. With the lateral constriction models, three flow rates were considered, $2.0 \mathrm{l} / \mathrm{sec}, 3.0 \mathrm{l} / \mathrm{sec}$, and 4.0 $\mathrm{l} / \mathrm{sec}$, whereas one flowrate was examined for the orifice flow condition of $4.5 \mathrm{l} / \mathrm{sec}$. In Table (1) Froude numbers were calculated for the uniform flow depths, are ranged from 0.297 to 0.407 which indicates subcritical flow conditions, the water temperature was $\left(20 C^{\circ}\right)$ and viscosity was $8.90 \times$ 10-4 Pa.s.

Table 1. Establishing uniform flow conditions

\begin{tabular}{|c|c|c|c|c|c|}
\hline $\begin{array}{c}\mathrm{Q} \\
(\mathrm{l} / \mathrm{s})\end{array}$ & $\begin{array}{c}\mathrm{H} \\
(\mathrm{cm})\end{array}$ & $\begin{array}{c}\mathrm{V=Q} / \mathrm{A} \\
(\mathrm{m} / \mathrm{sec})\end{array}$ & $\begin{array}{c}\mathrm{Re}= \\
\mathrm{VH} / \mathrm{v}\end{array}$ & $\begin{array}{c}\mathrm{Fr}= \\
\mathrm{V} /(\mathrm{gH}) 0.5\end{array}$ & Flow type \\
\hline 2 & 3.20 & 0.208 & 6627 & 0.371 & Free flow \\
\hline 3 & 4.52 & 0.221 & 9940 & 0.332 & Free flow \\
\hline 4 & 5.90 & 0.225 & 1325 & 0.297 & Free flow \\
\hline 4.5 & 6.40 & 0.234 & 1491 & 0.296 & Orifice flow \\
\hline 7 & 7.98 & 0.292 & 2319 & 0.330 & Weir flow \\
\hline 8.5 & 9.20 & 0.307 & 2816 & 0.324 & Weir flow \\
\hline 12 & 9.93 & 0.402 & 3976 & 0.407 & Weir flow \\
\hline 15 & 11.5 & 0.433 & 4970 & 0.407 & Weir flow \\
\hline
\end{tabular}

Water surface profile measurements were scheduled in Table 2 in terms of upstream water level $h_{u}$, downstream water level $h_{d}$, and water level difference $\Delta h$ in three different groups, $A 1, B 1$, and $B 2$. $B 1$ and $B 2$ are the flow conditions in the vicinity of the lateral abutment for the obstacles with the dimensions $(L s=9 \mathrm{~cm}$ and $L C=9 \mathrm{~cm})$ and $(L s=20 \mathrm{~cm}$ and $L C=15.5 \mathrm{~cm}$ ) respectively. While $A 1$ is the flow condition for the submerged rectangular bridge.

Table 2. Flow conditions

\begin{tabular}{|c|c|c|c|c|c|c|}
\hline $\begin{array}{c}\text { Stat } \\
\mathrm{e}\end{array}$ & $\mathrm{Q}$ & $\mathrm{h}_{\mathrm{u}}$ & $\mathrm{h}_{\mathrm{d}}$ & $\Delta \mathrm{h}$ & $\mathrm{V}_{\mathrm{w}}$ & $\begin{array}{c}\mathrm{Fr}=\mathrm{Vw} / \\
\sqrt{H g}\end{array}$ \\
\hline & $(\mathrm{l} / \mathrm{s})$ & $(\mathrm{cm})$ & $(\mathrm{cm})$ & $(\mathrm{cm})$ & $(\mathrm{m} / \mathrm{sec})$ & $(-)$ \\
\hline A1 & $15.0-$ & $12.9-$ & $10.9-$ & $2.0-$ & $0.433-$ & $0.407-$ \\
& 4.5 & 3.5 & 2.85 & 0.65 & 0.208 & 0.371 \\
\hline B1 & $4.0-$ & $6.25-$ & $5.62-$ & $0.63-$ & $0.225-$ & $0.296-$ \\
& 2.0 & 3.51 & 3.0 & 0.51 & 0.208 & 0.371 \\
\hline B2 & $4.0-$ & $6.89-$ & $4.83-$ & $2.06-$ & $0.225-$ & $0.296-$ \\
& 2.0 & 4.27 & 2.2 & 2.07 & 0.208 & 0.371 \\
\hline
\end{tabular}

In the case of $A 1$, the orifice flow rate is calculated from the total flowrate minus the overtopping flowrate. Broad crested weir flow (overtopping) was calculated from $Q=V A_{w}$, where $Q$ is the overtopping flowrate, $A_{w}$ is the cross-sectional area of flow over the bridge deck (broad crested weir), and is equal to flow depth over the weir, $h_{w}$ multiplied by bridge deck width which is equalling to the flume width $\mathrm{W}$. Flow velocity over the weir was measured by using Nixon probe velocimetry. For the weir flow, six different sections were used to measure the point velocities at two different depths $(\mathrm{H}=0.2$ and $\mathrm{H}=0.8)$ at each section.

\section{Dimensionless Analysis Subtitle}

The flow-through bridge opening is a function of hydraulic properties, fluid characteristics, and channel geometries, by using the Buckingham $\pi$ theory, the following dimensionless formula was found as:

$$
f_{1}\left(h_{u}, h_{d}, h_{w}, B, W, V_{d}, \rho, \mu, g\right)=0
$$

Where $h_{u}$ is the upstream water level, $h_{d}$ is the downstream water level, $h_{w}$ is the water level above the weir, $B$ is the free opening width, $W$ is the channel width, $V_{d}$ is the downstream velocity, $\rho$ is the mass density, $\mu$ is the water dynamic viscosity, and $g$ is the gravitational acceleration.

By applying Buckingham's $\pi$ theory, three independent variables were selected, $V_{d}, h_{w}, \rho$. then the new dimensionless relationship is given by:

$$
f_{2}\left(\frac{h_{u}}{h_{w}}, \frac{h_{d}}{h_{w}}, \frac{B}{h_{w}}, \frac{W}{h_{w}}, \frac{\mu}{V_{d} h_{w} \rho}, \frac{g h_{w}}{V_{d}{ }^{2}}\right)=0
$$


From eq. (2) $\frac{V_{d} h_{w} \rho}{\mu}=R_{e}$ (Reynolds number) which is insufficient in open channel flow so we can neglect it and $\frac{V_{d}^{2}}{g h_{w}}=F_{r}^{2}$ (Froude number) so by multiplying and dividing as well as subtracting variables, equation (2) can be written as:

$$
f_{3}\left(\frac{h_{u}-h_{d}}{h_{w}}, \frac{B}{W}, F_{r}\right)=0
$$

The difference between upstream and downstream water levels around the structure is defined as ( $\left.\Delta h=h_{u}-h_{d}\right)$ from equation (3).

\section{RESULTS AND DISCUSSIONS}

\subsection{WATER SURFACE FLOW}

The measured data were compared with Yarnell's formula to calculate the difference between water levels upstream and downstream bridge piers and abutments, in which Yarnell, 1934 assumed that

$$
\Delta h=2 k\left(k+5 F_{r}^{2}-0.6\right)\left(\alpha+15 \alpha^{4}\right) \frac{v_{d}^{2}}{2 g}
$$

where $k$ is a coefficient reflecting the pier and abutment shape, $\alpha$ is the ratio of flow area obstructed by the pier and abutment to the total flow area downstream. According to Yarnell's charts and abutments shape in the present work, the values of $k$ and $\alpha$ were 0.867 and 0.483 respectively.

From dimensional analysis and parameters results from Buckingham's theory, we can develop a theoretical equation for calculating the difference between water level upstream and downstream abutment similar to that equation developed by Yarnell (1934).

$$
\Delta h=c_{1} h_{w}+c_{2} B / W^{c_{3}}+c_{4} F_{r}^{c_{5}}
$$

By using SPSS Ver.11 statistical programming and depending on eq. 5 we can find constants ( $c 1$ to c5) then eq. 5 can be written as:

$$
\Delta h=0.177 h_{w}-0.665 \frac{B}{W}^{-0.04}+0.694 F_{r}^{0.0157}
$$

With correlation coefficient 0.9 and relative error compared with experimental data measured and computed using Yarnell equation not exceed $5 \%$.
Fig. 2 and 3 show the relationship between normalized measured and calculated $\Delta h$ for all flow cases calculated by Yarnell and eq. 6 respectively. From the Figures, it can be seen the good agreement between the measured and calculated data with maximum error doesn't exceed $5 \%$.

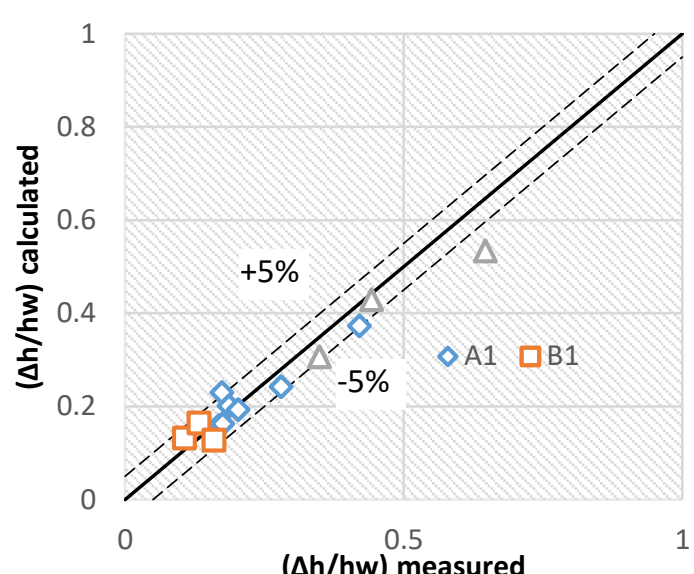

Fig. 2. Relationship between measured and calculated $\Delta h$ from Yarnell's eq. (4) concerning uniform flow (flow over the weir)

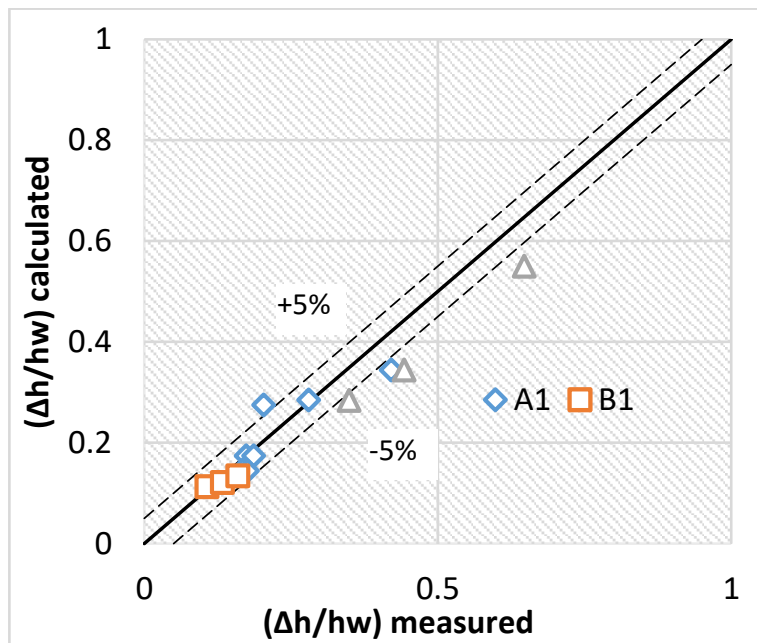

Fig. 3. Relationship between measured and calculated $\Delta h$ from eq. (6) to uniform flow (flow over the weir)

\subsection{DRAG COEFFICIENT CALCULATION}

By applying momentum principle, neglecting friction effect the equation can be written as:

$$
p 1-p 2-F_{d}=\rho Q(V 2-V 1)
$$

Where $\mathrm{p} 1$ and $\mathrm{p} 2$ are hydrostatic pressure forces upstream and downstream abutment position, $F_{d}$ is the drag force, $Q$ is the discharge, 0 is the mass density, V1 and V2 are average velocities upstream and downstream respectively. 
The drag force can be written as follows [8]:

$$
F_{d}=\frac{1}{2} C_{D} \rho V_{1}^{2} A
$$

where $C_{D}$ is the drag coefficient, $\mathrm{A}$ is the crosssectional area, $A=b * h$, where $b$ is the width of the bridge, and $\mathrm{h}$ is the height of the obstacle. The head loss $\Delta \mathrm{h}$ can be written as

$$
\Delta h=C_{L} \frac{V^{2}}{2 g}
$$

where $C_{L}$ is the loss coefficient, substitution equations (8) and (9) into Eq. (7) leads to the relationship between $C_{L}$ and $C_{D}$

$$
C_{D}=C_{L} \frac{h u}{h}
$$

where $h_{u}$ is upstream water level.

The hydraulic loss coefficients, $C_{L}$ of the lateral constrictions and that, is denoted by $A 1$ for bridge case as well as B1 and B2 for the lateral constrictions $(9 \mathrm{~cm} \times 9 \mathrm{~cm})$ and $(20 \mathrm{~cm} \times 15.5 \mathrm{~cm})$ respectively is mainly a function of the opening ratio with the ranges of 0.7 to 0.483 . Decreasing the opening ratio results in a high hydraulic loss coefficient. The impact of the blockage ratio on the hydraulic loss coefficient showed an increase of 1-2 times when the $\mathrm{B} / \mathrm{W}$ was changed from 0.70 to 0.483, Fig.4. [5] computed the values of the local loss coefficient $\left(\Delta h / v^{2} / 2 g\right)$ between 0.5 to 10 for free and submerged flows in the vicinity of an arch bridge model. Local loss coefficient was computed in terms of the downstream velocity, $V_{d}$ from equation 9 , these values are within the range of $(2$ to 5) for a submerged rectangular bridge (denoted by $\mathrm{A} 1$ ). Finally, the local loss coefficient of fully flowing flow was between 1and 2.9.

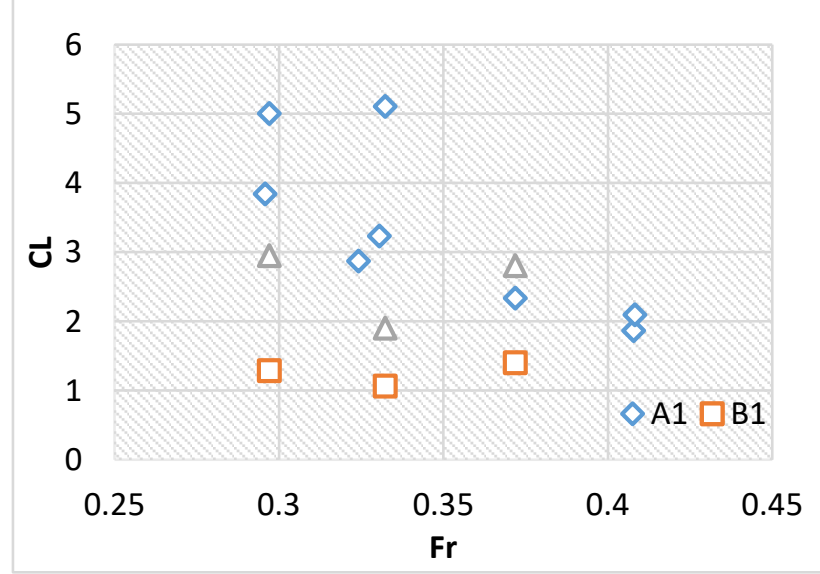

Fig. 4. Relationship between Froude number and hydraulic loss coefficient
Fig. 5 represents the relation of drag coefficient and Froude number; it can be seen that for the low Froude number, the measurements were observed lower than that value in higher numbers for (B1 and B2) because increasing boundary layer near and around abutments in small discharges (low Froude number) and that caused increasing drag coefficient [20]. The measurements of case $A 1$ are greater than that value in case B2 and B1 respectively for the same value of Froude number because increasing surface area impacting water flow then increasing drag coefficient [20]. While for large values of Froude number it showed that the drag coefficient for case $A 1$ is minimum vales compared with cases (B1 and B2) which have the same value of drag coefficient.

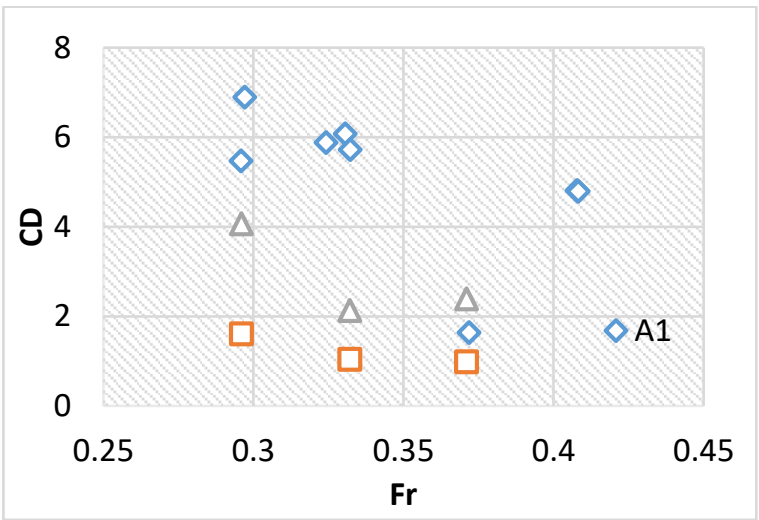

Fig. 5. Relationship between drag coefficient and Froude number

The wall effect on the drag coefficient on a lateral constriction and bridge deck slab models located within a laboratory flume is due to the narrow flume width of $30 \mathrm{~cm}$, so the calculated drag coefficient $C_{D}$ values were corrected for flow blockage as proposed by the following equation [18]:

$$
C_{D c}=C_{D}\left(1-\frac{b}{W}\right)^{2}
$$

Where, b/ $W$ is the blockage ratio, which is defined as the ratio between the obstacle width, $b$, to the flume width, $W$. The variation of the drag coefficient values is due to the parameters used in describing the drag coefficient.

Fig.6 shows the corrected values of drag coefficient which is denoted by $C_{D c}$ from equation (11) versus Froude number Fr. It was found that the maximum drag coefficient $C_{D}$ values did not exceed 3.5 for case $A 1$ with an average value $C_{D}=2.1$. However, the drag coefficient values for the cases $\mathrm{B} 1$ and $\mathrm{B} 2$ range is 0.5 to 2 . As the blockage ratio is 
increased, the drag coefficient is increased. [19] studied the drag coefficient for a single square obstacle which showed good agreement with the earlier studies of the drag coefficient value $C_{D}=0.55$ to $2.11,[19]$.

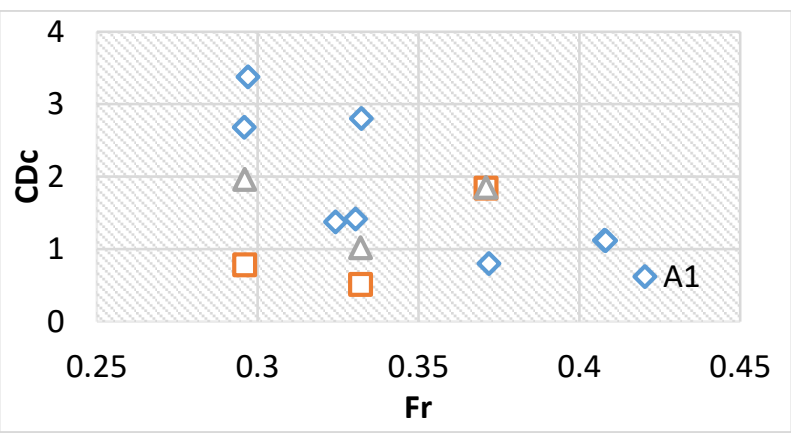

Fig. 6. Relationship between the corrected drag coefficient and Froude number

Fig.7. summarizes the relationship between the Froude number and the $h_{u} / h_{w}$ ratio. It was shown that the Froude number increases with increasing values of (hu/hw) for the cases B1 and B2 (side abutments). At the same values of the Froude number, values of $\left(h_{u} / h_{w}\right)$ in case $B 1$ have lower values than that in case B2. For case $A 1$ (weir flow condition), the Froude number is increased when the values of $\left(h_{u} / h_{w}\right)$ increase. In the case of $A 1$, because much water discharges through the bridge opening, Froude number $\mathrm{Fr}$ increases with increasing the $h_{u} / h_{w}$ ratio.

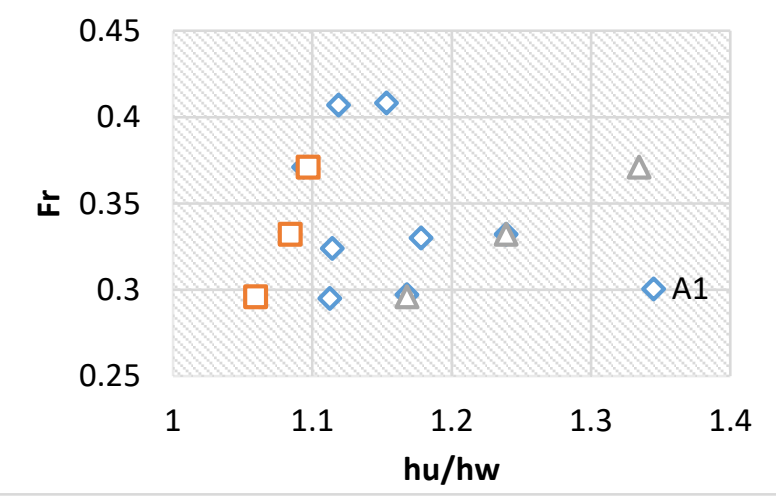

Fig.7. Relationship between $h_{u} / h_{w}$ and Froude number

\section{CONCLUSIONS}

In this research, two bridge models and three flow conditions were investigated. A sidewall abutment (lateral constriction) and submerged rectangular bridge models were examined. For the submerged bridge deck, two types of flows; orifice flow and weir flow were investigated and numbered by $\mathrm{A} 1$. For the lateral constriction, the free flow condition was tested using two boxes of different sizes that result in an opening ratio of 0.70 and 0.483 and denoted by $\mathrm{B} 1$ and $\mathrm{B} 2$ respectively. This research aims to investigate the hydraulic characteristics of flow through partially or fully bridge opening. From the experimental investigation the following conclusions have been drawn:

* The height of the water depth a bit upstream of the bridge constriction is decreased as the water depth is increased. Increasing flow rate results in an increase in the water depth, in which the flow rate accelerates to drain through the orifice and the weir flow. This state of flow causes the difference between the water depths a bit upstream the edge of the bridge is decreased at high discharges.

*The values of hydraulic loss coefficient $\mathrm{CL}$ and drag coefficient $C_{D}$ were calculated and compared concerning $\mathrm{Fr}$, the hydraulic loss coefficient increases 1-2 times when the opening decreased.

* The calculated head loss $(\Delta \mathrm{h})$ equation for bridge models was developed from the dimensional analysis and compared with experimental data and the Yarnell equation which showed a percentage error not exceed $5 \%$.

* The drag coefficient values for B1 and B2 are ranged from 0.5 to 2.0, and for the submerged bridge model $A 1$ was in the range of (0.5-3.5) with an average of 2.1.

\section{ACKNOWLEDGMENTS:}

The first author would like to express his special thanks to the hydraulic laboratory at Cardiff University for doing experiments and Mustansiriyah University for its continued support to achieve this research. Many thanks to those who encourage us to perform this research.

The authors have declared no conflict of interest

\section{NOTATIONS:}

$\mathrm{C}_{\mathrm{D}} \quad$ Drag coefficient

$\mathrm{C}_{\mathrm{L}} \quad$ Hydraulic loss coefficient

$\mathrm{h}_{\mathrm{w}}$ the water level above the weir, $\quad \mathrm{L}$ The difference between $\mathrm{L}$ upstream and downstream

$\Delta_{\mathrm{h}}$ water head

B free flow width 
b Width for submerged bridge $\mathrm{L}$ deck

Fr Froude number

g gravitational acceleration. $\quad \mathrm{LT}^{-2}$

h Height of Abutment L

$\mathrm{h}_{\mathrm{u}} \quad$ Approach water head L

$h_{d}$ Downstream water level L

$h_{0}$ height below the deck for $L$ submerged bridge deck

$h_{\mathrm{t}}$ the deck thickness for $\mathrm{L}$ submerged bridge deck

$\mathrm{h}_{\mathrm{u}} \quad$ Upstream water level $\mathrm{L}$

$L_{c} \quad$ Abutment width perpendicular $L$ to the flow direction

$L_{s} \quad$ Abutment length in the direction $L$ of flow

Q The discharge $\quad \mathrm{L}^{3} \mathrm{~T}^{-1}$

$\mathrm{R}_{\mathrm{e}} \quad$ Reynolds number

V Flow velocity

$\mathrm{LT}^{-1}$

W channel width

$\mu \quad$ water dynamic viscosity

$\mathrm{MLT}^{-2}$

$\mathrm{P}$ mass density $\mathrm{ML}^{-3}$

$L \quad$ length in the direction of flow for $\quad L$ submerged bridge deck

\section{REFERENCES}

[1] B. Akers, O. Bokhove, Hydraulic flow through a channel contraction: multiple steady states. Physics of Fluids, 20(5), 2008: 1-15. https://doi.org/10.1063/1.2909659

[2] S. Kara, S. Mulahasan, S. Thorsten, T.W. Sturm, Water surface response to flow through bridge opening, Presented at: Proceedings $7^{\text {th }}$ International Conference on Fluvial Hydraulics (River Flow), Lausanne, Switzerland, 2014.

http://dx.doi.org/10.1201/b17133-95

[3] S. Malavasi, A. Guadagnini, Interactions between a rectangular cylinder and a freesurface flow. Journal of Fluids and Structures, 23 (8), 2007: 1137-1148.

https://doi.org/10.1016/i.jfluidstructs.2007. 04.002

[4] J. Hunt, G. Brunner, Flow transitions in bridge backwater analysis US Army Corps of
Engineers, Institute of Water Resources, Hydrological Engineering Centre, Research Document No.42, 1995.

[5] J. Martin-Vide, J. Prio, Backwater of arch bridges under free and submerged conditions. Journal of Hydraulic Research, 43 (5), 2005: 515-521. https://doi.org/10.1016/i.jfluidstructs. 2007. 04.002

[6] S. Al-Hashimi, S.A.T. Al-Osmy, S. Mulahasan, Water surface profile and flow pattern simulation over a bridge deck slab. Journal of Engineering and Technology, 15 (1), 2020: 291-304.

[7] C. Suribabu, R. Sabarish, R. Narasimham, A. Chandharu, Backwater rise and drag characteristics of bridge piers under subcritical flow conditions EWRA European Water 36, 2011: 27-35.

[8] D. Yarnell, Bridge piers as channel obstructions, Technical Bulletin No. 442, United States Department of Agriculture Washington, D.C, 1934.

[9] J. Dravidian, P. Carrigan, J. Shen, Flow through openings in width constrictions, River Hydraulic, Geological Survey WaterSupply Paper 1369-D, United States Government, Washington, 1962. https://doi.org/10.3133/wsp1369D

[10] T. Pieck, A. Havlik, D. Mattas, K. Mares, Hydraulic calculation of bridges at high water stages. Journal of Hydraulic Research, 45 (3), 2007: 400-406.

https://doi.org/10.1080/00221686.2007.952 1773

[11] A. Barbhuiya. S. Dey, Turbulent flow measurement by the ADV in the vicinity of a rectangular cross-section cylinder placed at a channel sidewall. Flow Measurement and Instrumentation, 15 (4), 2004: 221-237. https://doi.org/10.1016/j.flowmeasinst.2004 .02 .002

[12] A. Sarker, Flow measurement around scoured bridge piers using Acoustic-Doppler Velocimeter (ADV). Flow Measurement and Instrumentation, 9 (4), 1998: 217-227.

https://doi.org/10.1016/S09555986(98)00028-4

[13] S. Dey, A. Barbhuiyab, Velocity and turbulence in a scour hole at a vertical-wall abutment. Flow Measurement and Instrumentation, 17 (1), 2006: 13-21. https://doi.org/10.1016/j.flowmeasinst.2005 .08 .005 
[14] S. Kara, T. Stoesser, T.W. Sturm, S. Mulahasan, Flow dynamics through a submerged bridge opening with overtopping. Journal of Hydraulic Research, 53(2), 2015: 186-195.

https://doi.org/10.1080/00221686.2014.967 $\underline{821}$

[15] Y. Veliskvai, Z. Chara, R. Schugerl, R. Dulovicovaiter, CFD simulation of flow behind overflood obstacle. Journal of Hydrology and Hydromechanics, 66 (4), 2018: 448-456. https://doi.org/10.2478/johh-2018-0028

[16] K.S. Yoon, S.O. Lee, S.H. Hong, Time-averaged turbulent flow field through the various bridge contractions during large flooding. Water, 11 (1), 2019: 143.

https://doi.org/10.3390/w11010143
[17] T.K.C. Thai, Numerical simulation of the turbulent flow over submerged bridge decks. Magazine of Civil Engineering, 85 (1), 2019: 15-27.

https://doi.org/10.18720/MCE.85.2

[18] S. Mulahasan, T. Stoesser, Flow resistance of in-line vegetation in open channel flow, International Journal of River Basin Management, 15 (3),2017: 1-14. https://doi.org/10.1080/15715124.2017.130 $\underline{7847}$

[19] F.H. Robertson, G.F. Lane-Serff, Drag on pairs of square section obstacles in free-surface flows. Phys. Rev. Fluids, 3 (12), 2018: 123802. https://doi.org/10.1103/PhysRevFluids.3.12 $\underline{3802}$

[20] V. Chow, Open Channel Hydraulics. McGraw Hill company, 1959, p.388. 